$$
\begin{aligned}
& \text { CONF- } 9606 / 16--69 \\
& \text { UCRL-JC-123559 }
\end{aligned}
$$

\title{
The Impact of Pulsed Irradiation Upon Neutron Activation Calculations for Inertial and Magnetic Fusion Energy Power Plants
}

\author{
J. F. Latkowski \\ J. Sanz \\ J. L. Vujic
}

RECEIVED

AUG 161996

O. S.JI

This paper was prepared for submittal to the American Nuclear Society 12th Topical Meeting on the Technology of Fusion Energy

Reno, NV

June 16-20, 1996

June 26, 1996

This is a preprint of a paper intended for publication in a journal or proceedings. Since changes may be made before publication, this preprint is made available with the understanding that it will not be cited or reproduced without the permission of the author. 


\section{DISCLAIMER}

This document was prepared as an account of work sponsored by an agency of the United States Government. Neither the United States Government nor the University of California nor any of their employees, makes any warranty, express or implied, or assumes any legal liability or responsibility for the accuracy, completeness, or usefulness of any information, apparatus, product, or process disclosed, or represents that its use would not infringe privately owned rights. Reference herein to any specific commercial product, process, or service by trade name, trademark, manufacturer, or otherwise, does not necessarily constitute or imply its endorsement, recommendation, or favoring by the United States Government or the University of California. The views and opinions of authors expressed herein do not necessarily state or reflect those of the United States Government or the University of California, and shall not be used for advertising or product endorsement purposes. 


\section{DISCLAIMER}

Portions of this document may be illegible in electronic image products. Images are produced from the best available original document. 
THE IMPACT OF PULSED IRRADIATION UPON NEUTRON ACTIVATION CALCULATIONS FOR INERTIAL AND MAGNETIC FUSION ENERGY POWER PLANTS

\author{
Jeffery F. Latkowski \\ Lawrence Livermore \\ National Laboratory \\ P. O. Box $808, \mathrm{~L}-481$ \\ Livermore, CA 94550 \\ (510) 423-9378
}

\author{
Javier Sanz \\ Instituto de Fusion Nuclear \\ Universidad Politécnica \\ de Madrid \\ J. Gutiérrez Abascal, 2 \\ 28006 Madrid, Spain
}

\author{
Jasmina L. Vujic \\ University of California \\ at Berkeley \\ 4105 Etcheverty Hall \\ Berkeley, CA 94720 \\ (510) 643-8085
}

\section{ABSTRACT}

Inertial fusion energy (IFE) and magnetic fusion energy (MFE) power plants will probably operate in a pulsed mode. The two confinement schemes, however, will have quite different time periods. Typical repetition rates for IFE power plants will be 1-5 Hz. MFE power plants will likely ramp up in current for about 1 hour, shut down for several minutes, and repeat the process. Traditionally, activation calculations for IFE and MFE power plants have assumed continuous operation and used either the "steady-state" (SS) or "equivalent steady-state" (ESS) approximations. ${ }^{1-5}$ It has been suggested recently that the SS and ESS methods may not yield accurate results for all radionuclides of interest. ${ }^{6}$ The present work expands that of Sisolak, et al. by applying their formulae to conditions which might be experienced in typical IFE and MFE power plants. In addition, complicated, multi-step reaction/decay chains are analyzed using an upgraded version of the $A C A B$ radionuclide generation/depletion code. ${ }^{7}$ Our results indicate that the SS method is suitable for application to MFE power plant conditions. We also find that the ESS method generates acceptable results for radionuclides with half-lives more than a factor of three greater than the time between pulses. For components that are subject to $0.05 \mathrm{~Hz}$ (or more frequent) irradiation (such as coolant), use of the ESS method is recommended. For components or materials that are subject to less frequent irradiation (such as high- $Z$ target materials), pulsed irradiation calculations should be used.

\section{INTRODUCTION}

Calculations of activation products are routinely performed for conceptual designs of IFE and MFE experimental facilities and power plants. These calculations typically assume some form of continuous opera- tion due to the complexity of modeling the actual, pulsed irradiation. IFE power plants will operate in a pulsed mode in which the dwell time, the time between shots, probably will be between $200 \mathrm{~ms}$ and $1 \mathrm{~s}$. The actual irradiation time for each shot in IFE power plants will be several orders of magnitude less than the dwell time - probably varying from $1 \mathrm{~ns}$ to $1 \mathrm{~ms}$ between components. In MFE power plants, the irradiation time will likely be orders of magnitude greater than the dwell time. One possible mode of operation for MFE power plants is the ramping-up of the toroidal current for about 1 hour. This would be followed by several minutes of shutdown, and the process would be repeated. Thus, the dwell time would be several minutes.

Sisolak, et al. define two methods for the approximation of pulsed irradiation: the steady-state (SS) and the equivalent steady-state (ESS) methods. ${ }^{6}$ Both methods conserve the total fluence. The SS method also conserves the total irradiation time, while the ESS method conserves the total operation time. In order to conserve both the total fluence and the total operation time, the ESS method scales the flux by the ratio of the irradiation time to the operation time. ${ }^{6}$ Although the SS and ESS approximations greatly simplify the process of calculating radionuclide inventories, Sisolak, et al. have demonstrated that they are not accurate when applied to MFE and IFE experimental facilities. ${ }^{6}$ The present work has evaluated the accuracy of the SS and ESS methods as they might be applied to typical MFE and IFE power plants.

\section{ANALYTIC INVESTIGATION}

Simple reaction/decay chains can be investigated analytically. Sisolak, et al. developed analytic expressions for a single, stable isotope that reacts to form a second, radioactive isotope. Equations (1) and (2) give 
the ratio of the inventory obtained with the approximation to the actual inventory for the second isotope for the SS and ESS methods, respectively. ${ }^{6}$ In both expressions, the ratio is a function of the radioactive half-life, the reaction cross section, the pulsed neutron flux, the irradiation time, and the dwell time The ratio for the SS method is also a function of the number of pulses. An ideal approximation would yield a ratio of one.

$$
\begin{aligned}
\frac{N 2_{s}}{N 2_{p}} & =\left[\frac{\exp \left(-n \sigma \phi_{p} \theta\right)-\exp (-n \lambda \theta)}{\exp \left(-\sigma \phi_{p} \theta\right)-\exp (-\lambda \theta)}\right] \\
& \times\left[\frac{\exp \left(-\sigma \phi_{p} \theta\right)-\exp (-\lambda(\theta+\Delta))}{\exp \left(-n \sigma \phi_{p} \theta\right)-\exp (-n \lambda(\theta+\Delta))}\right] \\
\frac{N 2_{\text {ess }}}{N 2_{p}} & =\frac{\left(\lambda-\sigma \phi_{p}\right) \theta}{(\theta+\Delta) \lambda-\sigma \phi_{p} \theta} \\
& \times\left[\frac{\exp \left(-\sigma \phi_{p} \theta\right)-\exp (-\lambda(\theta+\Delta))}{\exp \left(-\sigma \phi_{p} \theta\right)-\exp (-\lambda \theta)}\right]
\end{aligned}
$$

where:

$$
\begin{aligned}
& \lambda=\text { decay constant }\left(\mathrm{s}^{-1}\right) \\
& \sigma=\text { cross section }(\mathrm{b}) \\
& \phi_{\mathrm{p}}=\text { pulsed neutron flux }\left(\mathrm{n} / \mathrm{cm}^{2}-\mathrm{s}\right) \\
& \theta=\text { irradiation time }(\mathrm{s}) \\
& \Delta=\text { dwell time }(\mathrm{s}) \\
& \mathrm{n}=\text { number of pulses (dimensionless) }
\end{aligned}
$$

Equations (1) and (2) have been applied to MFE and IFE power plants, using reasonable estimates of the operating conditions that might be experienced. For an MFE tokamak power plant operating at $3000 \mathrm{MW}$ of fusion power with a $5 \mathrm{~m}$ major radius and a $2 \mathrm{~m}$ minor radius, the neutron flux incident upon the first wall would be about $3 \times 10^{14} \mathrm{n} / \mathrm{cm}^{2}-\mathrm{s}$. For an IFE power plant with a 3-m-radius spherical chamber, a $1 \mu$ s pulse length, and the same fusion power, the first wall flux would be about $2 \times 10^{20} \mathrm{n} / \mathrm{cm}^{2}-\mathrm{s}$. These fluxes have been used along with an MFE irradiation time of $3600 \mathrm{~s}$ and dwell time of $300 \mathrm{~s}$ and an IFE dwell time of 200 $\mathrm{ms}$. For the SS approximation, enough pulses have been used to obtain an operation time of 30 years $\left(2.4 \times 10^{5}\right.$ for the MFE case and $4.7 \times 10^{\circ}$ for the IFE case). A reaction cross section of $1 \mathrm{~b}$ has been assumed.

Figure 1 shows that both the SS and ESS methods yield reasonable results for MFE power plant conditions. The ESS method does not perform as well as the SS method as it slightly underestimates the inventories of radionuclides with half-lives less than about thirty times the dwell time of $300 \mathrm{~s}$. The SS method overestimates the inventories of radionuclides with half-lives of 3 hours to 3 years. The overestimation, however, never exceeds nine percent.

Figure 1. The SS and ESS methods both appear to be adequate for use under MFE power plant conditions.

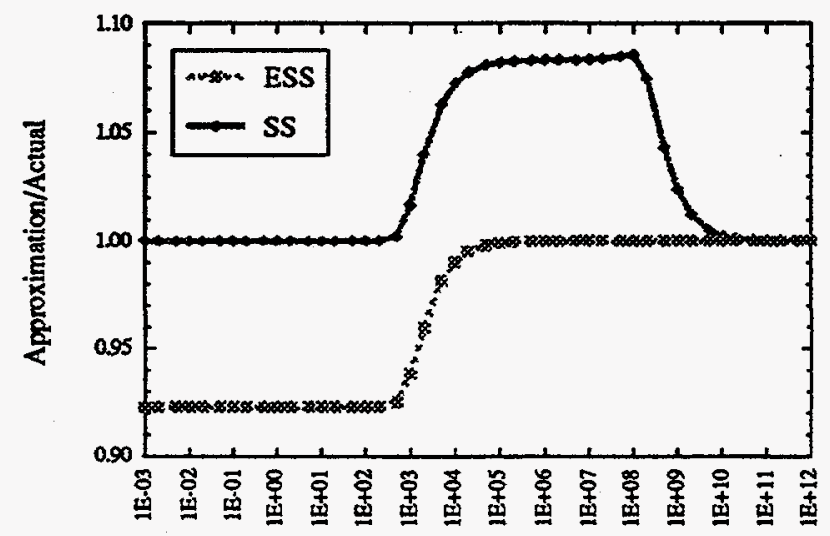

Half-life (seconds)

Although the SS method performs quite well when used for MFE conditions, it does not fare as well when used under IFE power plant conditions. Figure 2 shows that the SS method, when applied to IFE power plant conditions, overestimates the inventories of key radionuclides by as many as five orders of magnitude. Only radionuclides with half-lives of less than the irradiation time or greater than 3 years are accurately predicted by the SS method. Since a typical IFE power plant would experience only 80 minutes of irradiation time during 30 years of operation, failure of the SS method under these conditions is not surprising.

Figure 2. The SS method does not produce reasonable results when applied to IFE power plant conditions.

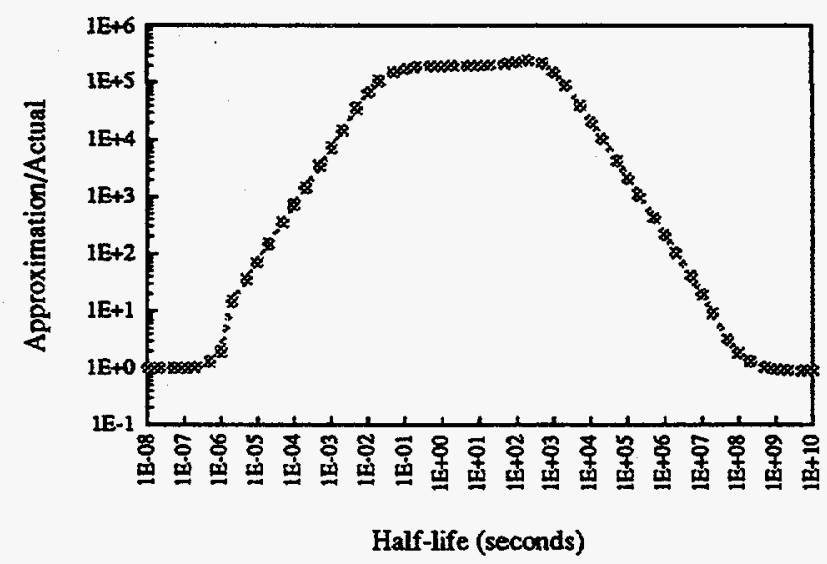

LATkowski: IMpact $(\rho \cdot 2)$ 
Figure 3 shows the results of use of the ESS method under likely IFE power plant conditions. The ESS method yields accurate results for radionuclides with half-lives greater than several times the dwell time of $\mathbf{2 0 0} \mathrm{ms}$. Fortunately, it is these radionuclides that are of concern for occupational, accident, and wastedisposal indices of radiological hazard.

The above analytical calculations are valid only for simple reaction/decay chains. Although the analytic results suggest trends in the usefulness of the SS and ESS methods, more complicated reaction/decay chains cannot be investigated analytically -- but require calculations to be performed with sophisticated computer codes.

Figure 3. The ESS method yields reasonäble results when applied to IFE power plant conditions.

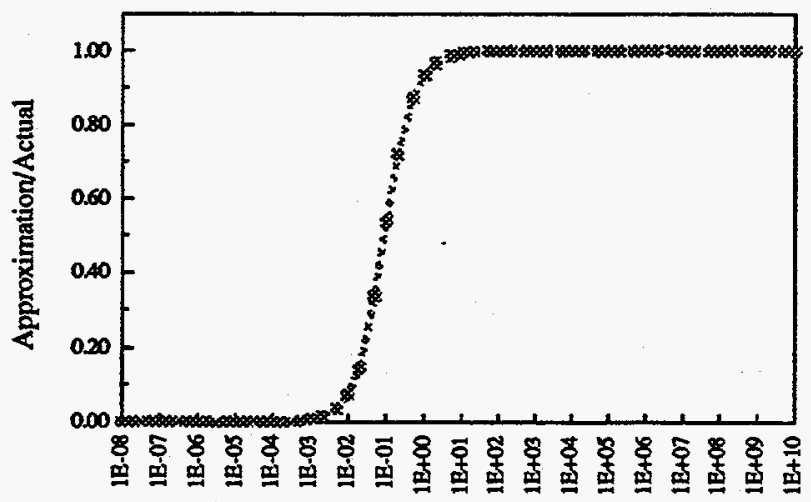

Half-life (seconds)

\section{COMPUTATIONAL INVESTIGATION}

Complicated reaction/decay chains cannot be investigated analytically. In the present work, the RADSAFE (Radiological Safety Analysis of Fusion Environments) computer system has been used to apply the ESS method to complicated reaction/decay chains. ${ }^{8}$ Results obtained with the ESS method are compared to those obtained by modeling the pulsed irradiation history without approximation.

\section{A. Computational Methods}

The calculational process, shown in Figure 4, begins with a geometric model created for use with the TART95 Monte Carlo transport code and its data libraries. ${ }^{9-11}$ TART95 calculates the energy-dependent neutron pathlengths in each of 175 energy groups. These pathlengths are converted by the TARTREAD code into neutron fluences, which are used with reaction cross sections by the $A C A B$ radionuclide generation/depletion code. ${ }^{12,7}$ The present work uses 175-group neutron cross sections provided by the EAF3.1 library. ${ }^{13}$ The PCROSS code and its data libraries generate 1-group "pseudo" cross sections that TARTREAD combines with collapsed neutron cross sections. ${ }^{14.15}$ Pseudo cross sections allow one to consider the effects of sequential charged-particle reactions. ${ }^{16-18}$

Figure 4. The $A C A B$ radionuclide generation/depletion code and the RADSAFE computing system are used to model complex reaction/decay chains.

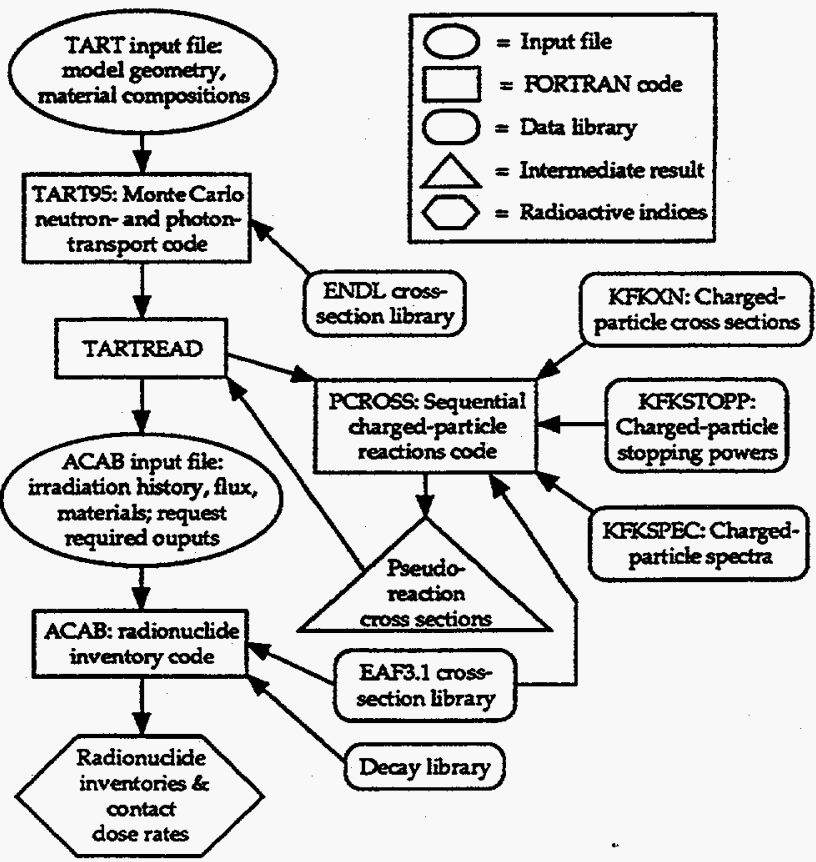

The ACAB code has been updated and is now able to simulate realistic irradiation sequences. A series of irradiation/cooling periods may be defined as a "unit" that is repeated a specified number of times. The final repetition of the unit may be followed by distinct irradiation/cooling periods. ACAB may be operated in either pulsed or steady-state modes, and thus, the benefits and consequences of using various approximate irradiation schemes may be investigated.

\section{B. Computational Results}

To assess the potential benefits and consequences of using approximations to model pulsed irradiation histories, two sets of calculations have been completed. In the first set, $1 \mathrm{~Hz}$ irradiation of ${ }^{56} \mathrm{Fe}$ in an IFE power plant has been simulated both with the ESS method and with the actual, pulsed irradiation history. Operation 
times as long as 1 year have been simulated. The second calculation simulated $5 \mathrm{~Hz}$ irradiation of natural iron and also used operation times as long as 1 year.

Modeling the actual, pulsed irradiation history is quite expensive -1 year of operation at $5 \mathrm{~Hz}$ required about 2000 hours CPU time on an HP/735 workstation (would be about 2500 hours on a Cray YMP). The ESS method required about $10 \mathrm{~s}$ of CPU time for all cases.

Figure 5 is a plot of ratio of radionuclide inventories obtained with the ESS method to those obtained by modeling the actual, pulsed irradiation history. Radionuclides with half-lives of more than $1 \mathrm{~s}$ and shutdown activities greater than $3.7 \times 10^{4} \mathrm{~Bq}(1 \mu \mathrm{Ci})$ have been included in the figure. For as much as 1 year of irradiation, the ESS method predicts the inventories of most radionuclides quite accurately. Inventories are significantly underestimated (by more than five percent) for only two radionuclides.

Figure 5. The ESS method accurately predicts radionuclides generated in 1 year of irradiation at 1 and $5 \mathrm{~Hz}$.

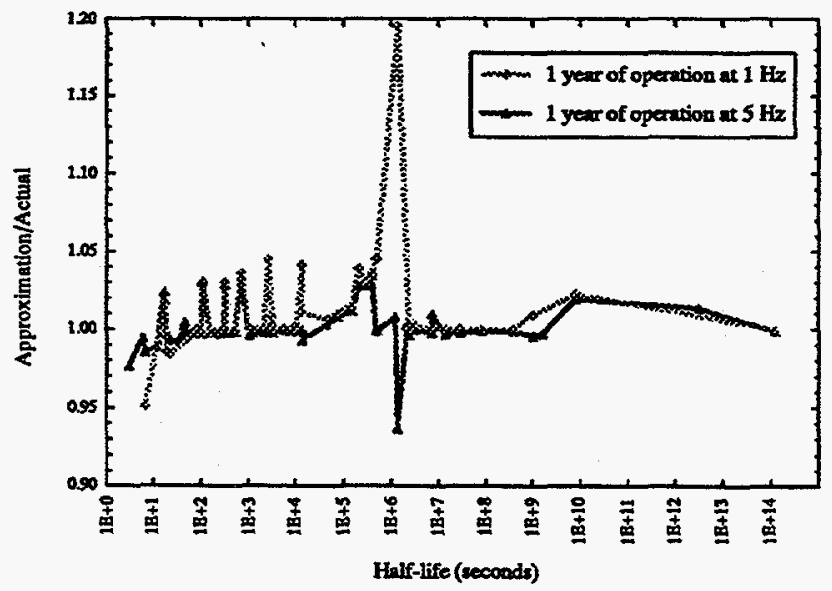

The ESS method has been used to model the irradiation of materials that are not subject to such high repetition rates - coolant and high- $Z$ target materials are irradiated on a much less frequent basis. Figure 6 shows that the ESS method produces reliable results for radionuclides with half-lives more than several times the dwell time. When used to model coolant activation a $5 \mathrm{~Hz}$ (dwell time of $20 \mathrm{~s}$ ), the ESS method produces reliable results for radionuclides of interest. When used to model the activation of high-Z target materials, which are irradiated only once per week, the ESS method fails to accurately predict the inventories of key radionuclides with half-lives of minutes to days.
Figure 6. The ESS method accurately predicts the inventories of radionuclides with half-lives greater than three times the dwell time.

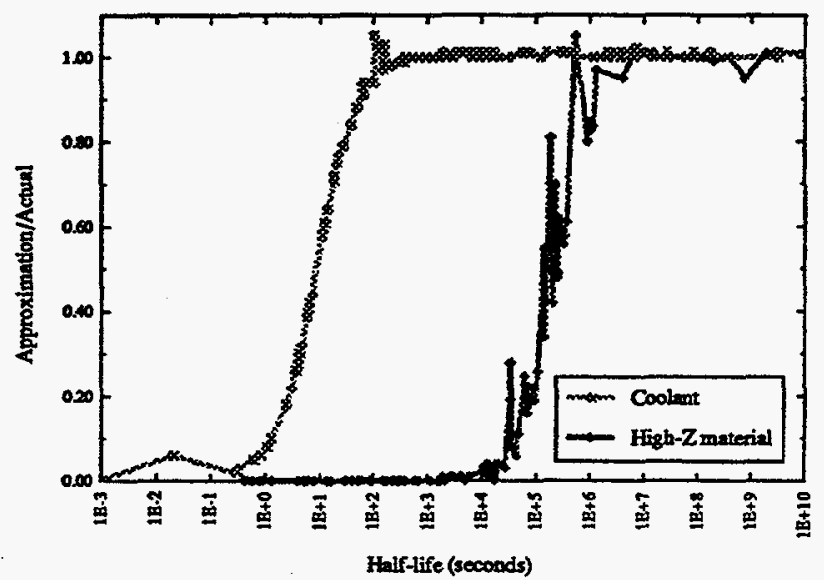

\section{CONCLUSIONS}

Use of the SS and ESS methods to model pulsed irradiation histories is appropriate in many cases. The SS method should not be used under IFE power plant conditions. The ESS method produces reliable results for radionuclides with half-lives of more than three times the dwell time. Thus, the ESS method may be used when radionuclides with half-lives of less than three times the dwell time are not deemed to be of importance. The ESS method should not be used with long dwell times such as high- $Z$ target activation.

Neither the SS nor the ESS method should be used to model pulsed irradiation in experimental facilities. Due to long dwell times, neither method accurately predicts the inventories of radionuclides that are of interest for occupational and accident analyses. It is worth noting that all calculations in support of the National Ignition Facility have modeled the actual, pulsed irradiation history.

\section{ACKNOWLEDGMENTS}

Work performed under the auspices of the U. S. Department of Energy by Lawrence Livermore National Laboratory under Contract W-7405-Eng-48.

\section{REFERENCES}

1. E. T. Cheng, R. A. Forrest, and A. Pashchenko, Report on the Second International Activation Calculation Benchmark Comparison Study, TSI Research Report TSIR-21 FINAL Draft, Nov. 1993. 
2 D. L. Smith, C. C. Baker, D. K. Sze, G. D. Morgan, M. A. Abdou, S. J. Piet, K. R. Schultz, R. W. Moir, and J. D. Gordon, "Overview of the Blanket Comparison and Selection Study," Fusion Technology, 8, 10, 1985.

3. J. P. Holdren, D. H. Berwald, R. J. Budnitz, J. G. Crocker, J. G. Delene, R. D. Endicott, M. S. Kazimi, R. A. Krakowski, B. G. Logan, and K. R. Schultz, Report of the Senior Committee on Environmental, Safety, and Economic Aspects of Magnetic Fusion Energy, Lawrence Livermore National Laboratory, UCRL-53766, Sept. 1989.

4. J. H. Pitts, R. F. Bourque, W. J. Hogan, W. R. Meier, and M. T. Tobin, The Cascade Inertial Confinement Fusion Reactor Concept, Lawrence Livermore National Laboratory, UCRL-LR-104546, Dec. 1990.

5. R. W. Moir, M. G. Adamson, R. O. Bangter, R. L Bieri, R. H. Condit, C. W. Hartman, P. A. House, A. B. Langdon, B. G. Logan, C. D. Orth, R. W. Petzoldt, J. H. Pitts, R. F. Post, R. A. Sacks, M. T. Tobin, W. H. Williams, T. J. Dolan, G. R. Longhurst, M. A. Hoffman, V. E. Schrock, P. F. Peterson, R. Y. Bai, X. M. Chen, J. C. Liv, D.K. Sze, and W. R. Meier, HYLIFE-II Progress Report, Lawrence Livermore National Laboratory, UCID21816, Dec. 1991.

6. J.E. Sisolak, S. E. Spangler, and D. L. Henderson, "Pulsed/Intermittent Activation in Fusion Energy Reactor Systems," Fusion Technology, 21, 2145, May 1992.

7. J. Sanz, J. F. Latkowski, M. T. Tobin, J. M. Perlado, D. Guerra, and A. S. Pérez, ACAB: Activation Code for Fusion Applications User's Manual V2.0, Lawrence Livermore National Laboratory, UCRL MA-122002, Sept. 1995.

8. J. F. Latkowski, Inertial Fusion Energy: A Clearer View of the Safety and Environmental Perspectives, Doctoral Dissertation, University of Califomia, Berkeley, Department of Nuclear Engineering, May 1996.

9. D. E. Cullen, A. L. Edwards, and E. F. Plechaty, TART95: A Coupled Neutron-Photon Monte Carlo Transport Code, Lawrence Livermore National Laboratory, UCRL-MA-121319, Jul. 1995.

10. R. J. Howerton, D. E. Cullen, R. C. Haight, M. H. MacGreagor, S. T. Perkins, and E. F. Plechaty, The
LLL Evaluated Nuclear Data Library (ENDL): Evaluation Techniques, Reaction Index, and Description of Individual Evaluations, Lawrence Livermore National Laboratory, UCRL-50400, Vol. 15, Part A, Sept. 1975.

11. D. E. Cullen, M. H. Chen, J. H. Hubbell, S. T. Perkins, E. F. Plechaty, J. A. Rathkopf, and J. H. Scofield, Tables and Graphs of Photon-Interaction Cross Section from $10 \mathrm{eV}$ to $100 \mathrm{GeV}$ Derived from the LLNL Evaluated Photon Data Library (EPDL), Lawrence Livermore National Laboratory, UCRL50400, Vol. 6, Rev. 4, Parts A \& B, Oct. 1989.

12. J. F. Latkowski, TARTREAD V1.0 User's Manual, Lawrence Livermore National Laboratory, UCRLMA-122003, Aug. 1995.

13. J. Kopecky, H. A. J. Van der Kamp, H. Gruppelaar, and D. Nierop, The European Activation File EAF-3 With Neutron Activation and Transmutation CrossSections, ECN-C-92-058, Sept. 1992.

14. S. Ravndal, P. Oblozinsky, S. Kelzenberg, and S. Cierjacks, User Manual for the KfK Code PCROSS, Kernforschungszentrum Karlsruhe, KfK 4873, Aug. 1991.

15. S. Cierjacks, P. Oblozinsky, and B. Rzehorz, Nuclear Data Libraries for the Treatment of Sequential $(x, n)$ Reactions in Fusion Materials Activation Calculations, KfK 4867, Institute for Materials, Kernforschungszentrum Karlsruhe, Jul.. 1991.

16. S. W. Cierjacks, P. Oblozinsky, S. Kelzenberg, and B. Rzehorz, "Development of a Novel Algorithm and Production of New Nuclear Data Libraries for the Treatment of Sequential $(x, n)$ Reactions in Fusion Material Activation Calculations," Fusion Technology, 24, 277-287, Nov. 1993.

17. K. Ehrlich, S. W. Cierjacks, S. Kelzenberg, and A. Moslang, "The Development of Structural Materials for Reduced Long-term Activation," Journal of Nuclear Materials, 215, 678-683, Sept. 1994.

18. J. F. Latkowski, J. Sanz, and J. L. Vujic, "Sequential Charged-Particle and Neutron Activation of Flibe in the HYLIFE-II Inertial Fusion Energy Power Plant Design," to be presented at the Twelth Topical Meeting on the Technology of Fusion Energy, American Nuclear Society, Jun. 1621, Reno, Nevada. 